\title{
Fármacos utilizados no tratamento das afecções neurológicas de cães e gatos
}

\section{Medical treatment of neurologic diseases of dogs and cats}

\author{
Isabelle Valente Neves ${ }^{1 *}$; Eduardo Alberto Tudury ${ }^{2}$; Ronaldo Casimiro da Costa ${ }^{3}$
}

\section{Resumo}

Este trabalho compreende uma revisão da literatura, dos diferentes fármacos utilizados na terapêutica das afecções neurológicas de cães e gatos, assim como sua indicação, dosagens, e duração do tratamento. Nesse contexto incluíram-se analgésicos, antibióticos, anticonvulsivantes, barbitúricos, anticolinesterásicos, antifúngicos, antifibrinolíticos, antiinflamatórios esteróides e não esteróides, antineoplásicos, antipsicóticos, ansiolíticos, antidepressivos, antioxidantes e varredores de radicais livres, diuréticos, fármacos utilizados nos distúrbios da micção, fitoterápicos, modificadores do metabolismo articular (nutracêuticos), relaxantes musculares e vitaminas.

Palavras-chave: Fármacos, doenças neurológicas, neurologia, cães e gatos

\begin{abstract}
A revision of the current literature regarding medical management of neurological diseases of dogs and cats is presented. The indications, doses, and duration of the recommended treatment of several medications are reviewed. The authors have reviewed analgesics, antibiotics, anticonvulsants, barbiturates, anticolinesterasics, antifungals, antifibrinolytics, steroidal and non-steroidal antiinflammatory, antineoplastics, antipsychotics, anxiolytics, antidepressants, free radical scavengers, diuretics, drugs used in the treatment of micturition disorders, phytotherapeutics, nutraceuticals, muscle relaxants and vitamins.
\end{abstract}

Key words: Medical management, neurological diseases, neurology, dogs and cats

\footnotetext{
${ }^{1}$ Médica Veterinária Autônoma. E-mail: isabellevalente@hotmail.com

${ }^{2}$ Professor Adjunto, Departamento de Medicina Veterinária, Universidade Federal Rural de Pernambuco - UFRPE. E-mail: tudury@nelore.npde.ufrpe.br

3 Professor de Neurologia e Neurocirurgia da The Ohio State University. ,E-mail: ronaldo.dacosta@cvm.osu.edu 


\section{Introdução}

Nos cães e gatos com afecções do sistema nervoso o tratamento pode ser dividido em médico e/ou cirúrgico. O tratamento médico é baseado na administração de fármacos que atuem diretamente no agente etiológico e proporcionem a cura da doença (ex.: antibióticos), ajam na diminuição da progressão da doença (ex.: neoplasias) ou é baseado no tratamento de suporte (ex.: cinomose).

Quanto ao fármaco adequado a ser utilizado, necessita-se saber a dose a ser empregada, o intervalo entre doses e a duração do tratamento, sempre relacionando a etiologia da afecção. Devese também ter conhecimento das particularidades existentes no sistema nervoso, como a barreira hematoencefálica. Sendo assim, o objetivo deste trabalho é relatar os diferentes fármacos utilizados atualmente na terapêutica das afecções neurológicas de cães e gatos, assim como sua indicação, dosagens, intervalo entre doses e duração do tratamento médico.

\section{Revisão de literatura}

\section{Analgésicos}

A dor em pacientes neurológicos traz conseqüências metabólicas e fisiológicas indesejáveis. Frequentemente observa-se dor espinhal ou neuropática como resultado do envolvimento das meninges, raízes nervosas e os nervos periféricos (BAGLEY, 2005).

\section{Analgésicos opióides}

Os analgésicos opióides são os fármacos mais utilizados e mais efetivos no controle da dor em animais. Eles funcionam ativando o sistema antinociceptivo, inibindo a projeção da dor (BAGLEY, 2005). Os analgésicos opióides afetam o processamento e a transmissão dos impulsos em níveis múltiplos do encéfalo e da medula espinhal interagindo com receptores específicos para inibir a transmissão de sinais dolorosos da zona radicular dorsal para os centros superiores. O tálamo e o córtex cerebral parecem ter alta densidade de receptores opióides. Além dos efeitos moduladores ao nível da medula espinhal, a ativação de receptores centrais inibe a transmissão de sinais dolorosos para centros superiores e, conseqüentemente, bloqueiam a percepção de estímulos dolorosos (BISTNER; FORD; RAFFE, 2002).

A morfina em cães e em gatos (baixas doses) é utilizada no tratamento da dor aguda e profunda e na medicação pré e pós-operatória. O efeito adverso da morfina em gatos é a hiperexcitabilidade que pode ser minimizada com o uso de tranqüilizantes ou baixas doses. Já os efeitos adversos relacionados aos cães e gatos são: euforia, hipotensão, prurido, depressão respiratória, edema, hemorragia cerebral, dificuldade de urinar, e redução da formação de urina. A dose recomendada para cães é $0,5-1 \mathrm{mg} / \mathrm{kg}$, via intramuscular (IM) ou subcutânea (SC); 0,050,4 mg/kg, q1-4h, IV; ou 0,2-1 mg/kg, q2-6h, IM ou $\mathrm{SC} ; 0,3-3 \mathrm{mg} / \mathrm{kg}$ q4-8h, por via oral (VO) e em gatos 0,05- 0,2 mg/kg, IM, SC (com cautela) (ANDRADE, 2002). Administrada pela via epidural apresenta a vantagem de que a ação analgésica terá duração de, aproximadamente, 24 horas (INTELIZANO, et al. 2002)

A hidromorfona é indistinguível da morfina em efeito e duração, embora não tenha sido relatada liberação de histamina em seu uso (CARROLL, 2005). Adosagem utilizada em pacientes com doença da medula espinhal é de $0,05-0,2 \mathrm{mg} / \mathrm{kg}$ em cães e $0,01 \mathrm{mg} / \mathrm{kg}$ em gatos q6h, IM ou SC (BAGLEY, 2005). A oximorfona também não causa liberação de histamina e é apropriada contra dor moderada a intensa. Embora a oximorfona em cães e gatos cause sedação, taquipnéia e, às vezes, hipotermia parece que causa menos vômito do que a morfina ou a hidromorfona (CARROLL, 2005).

O fentanil possui ação mais rápida e potente (75-125 vezes) do que a morfina, porém é de curta duração (30-45 minutos) (CARROLL, 2005). Tem 
sido utilizado em anestesiologia, como parte de protocolo de indução anestésica, em infusão contínua controlada ou em patch (adesivo) para promoção de analgesia por até $72 \mathrm{~h}$. O uso do adesivo de fentanil propicia excelente analgesia pós-operatória para pacientes que sofreram procedimentos neurocirúrgicos da coluna vertebral. Tem como efeitos adversos em cães à promoção de respiração ofegante, defecação e flatulências, além de através de estímulos sonoros poderem provocar respostas motoras (ANDRADE, 2002). No caso de infusão em velocidade constante uma dose inicial de $2 \mu \mathrm{g} /$ $\mathrm{kg}$, IV em cães e $1-2 \mu \mathrm{g} / \mathrm{kg}$, em gatos seguida por infusão (1-6 $\mu \mathrm{g} / \mathrm{kg} / \mathrm{h}$ em cães e $1-4 \mu \mathrm{g} / \mathrm{kg} / \mathrm{h}$, sendo que a duração da analgesia corresponde à duração da infusão mais 30 minutos (CARROLL, 2005).

A codeína vem sendo utilizada no controle da dor para animais com transtornos neurológicos sendo segura e efetiva em dor severa $(1 \mathrm{mg} / \mathrm{kg}, \mathrm{VO}$, q6h) (BAGLEY, 2005). Em cães saudáveis Carroll (2005), recomenda 1-2 mg/kg de codeína, VO, q8h, associado a acetaminofen (paracetamol), porém isso não deve ser utilizado em cães com hepatopatias ou propensos a anemia com corpúsculo de Heinz e também é estritamente contra-indicada essa associação em gatos. Pode-se administrar codeína sem acetaminofen (1-4 mg/kg VO, q1-6h), conforme necessário.

O butorfanol tem a vantagem de oferecer analgesia com depressão ventilatória mínima e doses subseqüentes não produzem depressão adicional. Em cães e gatos geralmente é administrado em casos de dor leve a moderada, a dose recomendada é $0,4-1 \mathrm{mg} / \mathrm{kg}, \mathrm{VO}, \mathrm{q} 8 \mathrm{~h}$ por 2-3 dias (CARROLL, 2005).

Buprenorfina é 30 vezes mais potente do que a morfina, sendo utilizado como potente analgésico, sendo a dose recomendada para cães 0,05-0,02 $\mathrm{mg} / \mathrm{kg}$, q4-8h, IM ou IV (ANDRADE, 2002). Segundo Carroll (2005), sua ação tem início em aproximadamente 30 minutos com duração de 4-8h.
Foi constatado experimentalmente que a utilização da naloxona também apresenta outros efeitos potencialmente importantes em Neurologia. Sendo demonstrado que em altas doses atuará melhorando o fluxo sanguíneo após o trauma medular e aumentando a recuperação da função neurológica, também podendo ser administrados logo após o trauma com finalidade de proteger o paciente, durante o transporte (BRAUND, 2003).

\section{Antibióticos}

O sistema nervoso central (SNC) deve ser considerado como compartimento à parte em nosso organismo, isolado da circulação sistêmica, cujo acesso é altamente restrito, já que é completamente envolvido por uma camada celular firmemente conectada entre si por junções oclusivas. Essa camada age como uma verdadeira membrana lipídica, formando duas barreiras: a barreira hematoencefálica (BHE) e a barreira hematoliquórica (BHL) responsáveis pela manutenção da homeostasia do SNC (VRIES et al., 1997). O endotélio da BHE não é fenestrado, mas possui junções oclusivas conectando os espaços intercelulares, restringindo a passagem de substâncias maiores que 10-15 $\mathrm{A}^{\circ}$ e tem ausência quase que total de vesículas pinocitóticas intracitoplasmáticas, impedindo o transporte transcelular (LIN; SÁ, 2002).

A atividade bactericida de um fármaco antimicrobiano no líquido cerebroespinhal (LCE) depende basicamente de sua concentração local e de sua atividade intrínseca no fluido infectado. A penetração dos agentes antimicrobianos no espaço liquórico ocorre predominantemente via difusão passiva, através de um gradiente de concentração (LEE et al., 2001). O transporte desses antibióticos através das barreiras que cercam o SNC depende de vários fatores, dos quais se destacam características dos fármacos como: lipossolubilidade, peso molecular, ligação a proteínas plasmáticas, capacidade de ionização e carga elétrica (LIN; SÁ, 2002). 
É importante ressaltar que, mesmo dentro do espaço liquórico, não há uma distribuição homogênea. Por exemplo, após a administração endovenosa de qualquer antibiótico capaz de penetrar no SNC, podemos encontrar concentrações máximas no LCE da região lombar, concentrações intermediárias na cisterna cerebelo medular, enquanto as concentrações ventriculares são provavelmente menores daquelas atingidas no LCE (NAU; SORGEL; PRANGE, 1998).

Ao escolher um agente antibiótico específico, devemos selecionar o agente bactericida que seja isoladamente menos tóxico e mais efetivo. A terapia deve ser direcionada basicamente para o agente causal, caso este possa ser identificado. Esta terapia deve ser mais prolongada que o tratamento para infecção similar em qualquer outra parte do corpo (NAU; SORGEL; PRANGE, 1998). É desejável que o antibiótico a ser utilizado atravesse a BHE em concentrações terapêuticas para que essas concentrações medicamentosas possam ser mantidas depois que a fase aguda da inflamação foi encerrada (FENNER, 1997).

Os antibióticos podem ser administrados aos animais sob suspeita de meningite bacteriana antes da obtenção dos resultados da cultura e dos testes de sensibilidade (FENNER, 1997). Alguns autores sugerem que deve ser administrada uma única injeção intravenosa de corticosteróides, antes da antibioticoterapia nos casos de meningite bacteriana (FENNER, 1997; LECOUTEUR; CHILD, 1997). Segundo Lin e Sá (2002), não é recomendável utilizar concomitantemente fármacos bactericidas e bacteriostáticos, uma vez que os últimos podem antagonizar a ação dos primeiros. Alguns medicamentos são tóxicos quando introduzidos diretamente no SNC (ex. administração intratecal), podendo causar convulsões como é o caso da penicilina, e os agentes podem não se difundir livremente através do LCE, especialmente se existe bloqueio ao fluxo deste líquido (FENNER, 1997).

Os antibióticos que atravessam a barreira hematoencefálica com ótima penetração são o trimetoprim, o metronidazol, o cloranfenicol e as sulfonamidas; com intermediária penetração são as penicilinas, as ampicilinas, a oxacilina, a carbenecilina, o ceftriaxone, o moxalactam e as tetraciclinas, e os com baixa penetração são as cefalosporinas de primeira geração, os aminoglicosídeos e a clindamicina (CHRISMAN, 1991). Várias cefalosporinas de terceira geração atingem concentrações efetivas no SNC, sendo consideradas os agentes mais adequados para tratamento da meningite por bactérias grampositivas (LECOUTEUR; CHILD, 1997).

Os antibióticos de eleição para as afecções neurológicas bacterianas são: ampicilina, cefalosporinas de $3^{\circ}$ geração, metronidazol, cloranfenicol e sulfa com trimetoprim (DEWEY, 2003). Em geral, as tetraciclinas, agentes bacteriostáticos de amplo espectro, atingem apenas concentrações efetivas no SNC quando as meninges estão inflamadas. Entretanto as tetraciclinas mais modernas (doxiciclina e minociclina) penetram no SNC melhor do que outras tetraciclinas, tendo melhor atividade contra microorganismos anaeróbios e alguns aeróbios. A minociclina apresenta também efeitos neuroprotetores antiapoptóticos para o SNC descobertos recentemente (STIRLING; KOOCHESFAAHANI; TETZLAFF, 2005). Nos casos de meningoencefalite riquetsial os antimicrobianos a serem empregados são a doxiciclina, as tetraciclinas ou o cloranfenicol (animais jovens antes da erupção dos dentes permanentes) (LECOUTEUR; CHILD, 1997). Diversas afecções riquetsiais como febre maculosa das montanhas rochosas e erliquiose, podem produzir meningoencefalite em cães e que o tratamento com tetraciclinas parece ser efetivo, em termos da resolução dos sinais sistêmicos e neurológicos (FENNER, 1997; DEWEY, 2003).

O metronidazol tem utilidade no tratamento da maioria das infecções anaeróbicas, é bactericida, e difunde-se bem por todos os tecidos, inclusive o SNC. Este agente terapêutico é utilizado em combinação com doses elevadas de penicilina, quando estão 
presentes microorganismos aeróbios. Quase todas as sulfonamidas penetram efetivamente no LCE. A sulfadiazina, ao se ligar menos às proteínas, em comparação com as outras sulfonamidas penetra no LCE e tecidos nervosos melhor que sulfametoxazol, sendo eficaz quando administrado VO. Não existem dados relacionados à concentração de trimetoprim no LCE de cães, porém geralmente a combinação de sulfadiazina com trimetoprim tem ação bactericida, e são efetivos no tratamento de algumas infecções bacterianas. O cloranfenicol atinge concentrações mais elevadas no LCE do que a maioria dos outros antibióticos; entretanto, este agente é bacteriostático, e foi demonstrado que muitos Staphylococcus são resistentes. O cloranfenicol pode ser administrado na dose de $40 \mathrm{mg} / \mathrm{kg}$, IV, q6h, ou $50 \mathrm{mg} / \mathrm{kg}$, VO, q $8 \mathrm{~h}$ em cães e 1-2 mg/kg, q12h em gatos, sendo seus efeitos adversos a gastrenterites em cães e gatos e a depressão da medula óssea em gatos (LEUCOTER; CHILD, 1997).

O tratamento da discoespondilite em animais sem deficiência neurológica, ou com deficiência neurológica leve, consiste no uso de antibiótico que seja efetivo contra o microorganismo, determinado por hemocultura, urocultura ou punção aspirativa. Os antibióticos que geralmente são efetivos para esta finalidade são as cefalosporinas, ou as penicilinas resistentes a beta-lactamase, como a oxacilina e a cloxacilina. A combinação de trimetoprim com sulfonamidas, ou cloranfenicol, é meios menos efetivos, mas menos dispendiosos, e podem ser efetivos em certos casos (LEUCOTER; CHILD, 1997). A antibioticoterapia é selecionada com base nos resultados de cultura e antibiograma. Se não houver resultados desses exames pode-se usar combinações de trimetoprim com sulfadiazina (15$30 \mathrm{mg} / \mathrm{kg}, \mathrm{q} 12 \mathrm{~h}$ ) ou cefalexina (30 mg/kg, q8h). Outros antibióticos que podem ser considerados em casos específicos são a enrofloxacina $(5 \mathrm{mg} / \mathrm{kg}, \mathrm{VO}$, q12h) e ciprofloxacina (5,5-11 mg/kg, VO, q12h), devendo-se continuar a antibioticoterapia por 6-8 semanas (CHRISMAN et al., 2005).
Nos casos de penetração do encéfalo no trauma craniano deve-se instituir imediatamente a antibioticoterapia de amplo espectro com o cloranfenicol ou sulfadiazina em associação com trimetoprim (DEWEY, 2003). Os antibióticos são a base para o tratamento dos abscessos cerebrais (FENNER, 1997; LEUCOTER; CHILD, 1997).

Nos casos de toxoplasmose pode-se usar a clindamicina (10 mg/kg, VO, q8h) ou sulfa associada ao trimetoprim (15 mg/kg, VO, q12h) com duração de 2-4 semanas, porém a associação de sulfonamidas (30 mg/kg, VO, q12h) e a pirimetamina $(0,25$ $0,5 \mathrm{mg} / \mathrm{kg}, \mathrm{VO}, \mathrm{q} 12 \mathrm{~h}$ ) durante 2 semanas é mais efetivo do que o trimetoprim (DEWEY, 2003). Nos casos de polirradiculoneurite ou miosite causadas por infecções de Toxoplasma gondii e Neospora caninum, recomenda-se o tratamento precoce com sulfadiazina associado à trimetoprim na dose de $15-30 \mathrm{mg} / \mathrm{kg}, \mathrm{VO}, \mathrm{q} 12 \mathrm{~h}$ ou ormetoprim associado à sulfadiometoxina na dose de $15 \mathrm{mg} / \mathrm{kg} \mathrm{VO}, \mathrm{q} 12 \mathrm{~h} \mathrm{e}$ clindamicina $5-0 \mathrm{mg} / \mathrm{kg}, \mathrm{VO}, \mathrm{q} 12 \mathrm{~h}$. Também pode ser utilizada a pirimetamina $0,5-1 \mathrm{mg} / \mathrm{kg}, \mathrm{q} 24 \mathrm{~h}$ por 3 dias e depois $0,25 \mathrm{mg} / \mathrm{kg}$ q24h, por mais 14 dias em cães e gatos, porém tem sido relatado supressão de medula óssea com o uso desse fármaco em pequenos animais (CHRISMAN et al., 2005).

O tratamento descrito para neosporose consiste na combinação de trimetoprim, pirimetamina, sulfonamidas e clindamicina. Contudo o grau de sucesso desses tratamentos é normalmente baixo, embora existam relatos de resolução completa dos sinais de neosporose em cão adulto com administração combinada de $1 \mathrm{mg} / \mathrm{kg}$, q24h de pirimetamina e $20 \mathrm{mg} / \mathrm{kg}$ de sulfadoxina durante 30 dias (PAIXÃO; SANTOS, 2004). A neosporose neonatal canina deve ser tratada com clindamicina $(12,5-18,5 \mathrm{mg} / \mathrm{kg}, \mathrm{VO}, \mathrm{q} 12 \mathrm{~h})$ ou com a associação de sulfadiazina $(30 \mathrm{mg} / \mathrm{kg})$ combinada com pirimetamina $(0,25-0,5 \mathrm{mg} / \mathrm{kg}$ q24h ou q12h) por duas a quatro semanas, esta última sendo mais efetiva (GENNARI; SOUZA, 2002). 


\section{Anticonvulsivantes e barbitúricos}

Os anticonvulsivantes são medicamentos utilizados em pacientes que apresentam convulsões ou epilepsia. São utilizados como medicamento único em cães que apresentam epilepsia ou em associação com outros medicamentos quando a origem das convulsões se deve a uma alteração metabólica ou orgânica em progressão (MANNO, 2003; PELLEGRINO, 2003).

A maioria dos anticonvulsivantes possuem efeito antiepileptogênico ou neuroprotetor. Este consiste no aumento da resistência a apoptose à qual conduze às crises convulsivas por meio de diferentes mecanismos. Por estes motivos, embora o animal não esteja livre das crises convulsivas, o dano que elas provocam será consideravelmente menor se o paciente for medicado, evitando a deterioração neuronal progressiva (MANNO, 2003; PELLEGRINO, 2003). Um dos problemas mais comuns no tratamento da epilepsia canina é o uso inadequado de anticonvulsivantes para esta espécie. Alguns fármacos utilizados em seres humanos são metabolizados tão rapidamente pelos cães que a concentração sérica terapêutica não pode ser alcançada. Poucas medicações eficazes em seres humanos podem ser apropriadas em cães, sendo o fenobarbital o mais indicado (ARIAS; NETO, 1999). O fenobarbital é uma medicação eficaz, segura, barata e com poucos efeitos colaterais além da sedação, sendo o fármaco de primeira escolha em cães e gatos, controlando de 60 a $80 \%$ dos cães epiléticos, caso a concentração sérica seja mantida dentro da faixa adequada (25-35 $\mu \mathrm{g} / \mathrm{mL}$ ) (CHRISMAN, 1997; BOOTHE, 1998; ARIAS; NETO, 1999; GASKILL et al., 1999; MAGUIRE et al., 2000; SILVA et al., 2006). Na experiência dos autores a dose de $2,5 \mathrm{mg} /$ $\mathrm{kg}, \mathrm{VO}, \mathrm{q} 12 \mathrm{~h}$ é suficiente para cães adultos. Em filhotes geralmente é necessário doses superiores a $4 \mathrm{mg} / \mathrm{kg}, \mathrm{VO}, \mathrm{q} 12 \mathrm{~h}$, variando de $4-8 \mathrm{mg} / \mathrm{kg}$ q12h (PODELL, 2004). Outros autores sugerem que em filhotes o fenobarbital seja administrado a cada 8 horas, devido à sua rápida metabolização nesta faixa etária (ARIAS; NETO, 1999). Caso o tratamento seja ineficaz e as convulsões não estejam sendo controladas, a dose poderá ser aumentada, objetivando o nível sérico de fenobarbital de 30 $\mu \mathrm{g} / \mathrm{mL}$ (CHRISMAN, 1997). Amaral e Larsson (2006), recomendam que a colheita, com propósito de monitoração, seja realizada quatro semanas após o início do tratamento, devido à ampla variação na meia vida de eliminação. O nível sérico de referência normal é $20-40 \mu \mathrm{g} / \mathrm{mL}$, porém o nível mais seguro é de $15-30 \mu \mathrm{g} / \mathrm{mL}$ e o ótimo está entre $20-25 \mu \mathrm{g} / \mathrm{mL}$, sendo o nível sérico acima de $35 \mu \mathrm{g} / \mathrm{mL}$ relacionado ao desenvolvimento de hepatotoxicidade (CHRISMAN, 1997; PODELL, 2004). Fenobarbital pode ser eficaz em casos de agressão relacionados à convulsão (HOUPT; REISNER, 1997), na terapia de suporte de animais com cinomose, neoplasias encefálicas e até mesmo em encefalopatia hepática, desde que o paciente apresente convulsões (DEWEY, 2003). Os efeitos adversos mais comuns associados ao uso contínuo do fenobarbital incluem polidipsia, polifagia, letargia e sedação, além da hepatotoxicidade (PODELL, 2004).

Devido à baixa solubilidade em lipídios, quando aplicado pela via intravenosa (IV) demora 15-20 minutos para ultrapassar a BHE, levando, portanto 20-30 minutos para controlar a crise convulsiva. Portanto nos casos de estado epiléptico recomendase à administração de diazepam, que atua em 2-3 minutos, seguida pela administração de fenobarbital em doses fracionadas de $2-4 \mathrm{mg} / \mathrm{kg}$ a cada 20 ou 30 minutos. Ao invés de doses fracionadas podese aplicar uma dose de ataque de $12-24 \mathrm{mg} / \mathrm{kg}$, IV, para que a concentração terapêutica seja atingida rapidamente, se for a primeira vez que o paciente estiver recebendo fenobarbital. Em ambos os casos o paciente deve ser monitorado, devido à possibilidade de ocorrência de depressão cardiorespiratória. Após o controle do estado epiléptico a administração deve ser mantida, na dose de $2-4 \mathrm{mg} / \mathrm{kg}$, q12h, até que o paciente esteja apto a receber medicação pela via oral. A epilepsia é considerada refratária ao fenobarbital quando o nível sérico terapêutico é atingido e o paciente continua a apresentar crises 
convulsivas em uma grande frequência. Não se pode considerar o paciente refratário ao fenobarbital se o nível sérico da medicação não foi avaliado, pois não existe correlação entre a dose oral e a concentração sérica (FARNBACH, 1984). A avaliação sérica do fenobarbital nos primeiros meses e depois, no mínimo, anualmente é uma condição absoluta para o uso correto do fenobarbital. Em casos verdadeiramente refratários, deve-se considerar a utilização de um segundo anticonvulsivante. Se esta necessidade for comprovada, é importante ressaltar que a terapia jamais deve ser cessada subitamente, devido ao risco do desenvolvimento de estado epiléptico grave. Assim, o próximo passo é a adição de um segundo anticonvulsivante, sendo o brometo de potássio o mais indicado (PEARCE, 1990; ARIAS; NETO, 1999).

Os gatos são mais sensíveis aos efeitos sedativos e eliminam mais lentamente o fenobarbital, sendo assim o seu nível sérico ideal é de $10-20 \mu \mathrm{g} / \mathrm{mL}$, e dose de 1-2 mg/kg, q24h, inicialmente à noite e posteriormente a cada 12 horas. Os gatos podem receber 1-2 $\mathrm{mg} / \mathrm{kg}$ de diazepam VO, q12h. Nos casos de epilepsia refratária é recomendada a associação do diazepam com o fenobarbital na dose de 0,5-2 mg/kg, dividida q8-12h (PODELL, 2004). O diazepam oral é anticonvulsivante efetivo em gatos, mas não em cães. O nível sérico é de 200500mg/mL (CHRISMAN, 1997).

$\mathrm{O}$ brometo de potássio $(\mathrm{KBr})$ possui uma estrutura molecular única comparada com os outros anticonvulsivantes. Ele não é metabolizado pelo fígado, podendo ser administrado em cães hepatopatas e é excretado pela urina (PEARCE, 1990). Devido a essas propriedades e a sua eficácia no tratamento das epilepsias em humanos se tornou uma opção no tratamento das epilepsias em cães. Não é recomendado em gatos, sendo relatados problemas respiratórios. Cristais de $\mathrm{KBr}$ dissolvidos em água bidestilada $(250 \mathrm{mg} / \mathrm{mL})$ e administrados na dose de $30 \mathrm{mg} / \mathrm{kg}$, VO, q24h numa das refeições quando associada ao fenobarbital, ou $40 \mathrm{mg} / \mathrm{kg}$, q24h quando usado isoladamente (PODELL, 2004).
Visto que KBr não está disponível comercialmente, cristais com graduação química podem ser obtidos e misturados por um farmacêutico em farmácias de manipulação. Os clientes devem ser instruídos para que usem luvas, porque o $\mathrm{KBr}$ pode ser absorvido através da pele e é tóxico para seres humanos. Os níveis séricos efetivos de $\mathrm{KBr}$ variam de 500$1500 \mu \mathrm{g} / \mathrm{mL}$ (PEARCE, 1990). O nível sérico na monoterapia do brometo é de 2000-3000mg/L e quando associado ao fenobarbital é de 15002500mg/L (PODELL, 2004). O KBr pode ser utilizado sem estar associado ao fenobarbital, podendo-se seguir o protocolo para o controle de convulsões em $24 \mathrm{~h}$ onde se utiliza $100 \mathrm{mg} / \mathrm{kg}$, VO, q6h atingindo em $24 \mathrm{~h}$ a dosagem de $400 \mathrm{mg} /$ $\mathrm{kg}$ que é utilizado para pacientes que precisam de proteção imediata, contudo a sedação e os potenciais distúrbios eletrolíticos associados a esta terapia são importantes. Outra opção é o protocolo para controle das convulsões em 5 dias onde as doses são de 90 $\mathrm{mg} / \mathrm{kg}$, q24h durante 5 dias atingindo-se $450 \mathrm{mg} /$ kg. Estes protocolos só são necessários caso haja urgência no controle das crises convulsivas, pois os efeitos adversos são importantes. Após atingir o nível sérico administra-se à dose de manutenção (PEARCE, 1990; LORENZ; KORNEGAY, 2006).

Outros fármacos pouco utilizados no tratamento da epilepsia são primidona, difenilhidantoina, clonazepam, ácido valpróico, carbamazepina, parametadiona, e clorazepato dipotássico (CHRISMAN, 1997), topiramato, lamotrigina, levetiracetam, zonisamida, gabapentina e felbamato (PODELL, 2004). Contudo a difenilhidantoína, o ácido valpróico, a carbamazepina não apresentam farmacocinética apropriada para cães e gatos, sendo portanto contra-indicadas. Outras medicações como no casos da zonisamida e do levetiracetam ainda não encontram-se disponíveis no Brasil. O topiramato usado em combinação com o fenobarbital ou brometo de potássio, mostrou-se eficaz no controle de crises epilépticas de difícil controle em cães e é, portanto uma opção terapêutica para o tratamento de cães com epilepsia refratária (ADEODATO, 
2005). Além de anticonvulsivante, a gabapentina pode ser usada para o tratamento da dor neuropática (MOREIRA, 2005).

Ainda não está bem comprovado o efeito protetor do tiopental e do pentobarbital sobre estruturas encefálicas envolvidas em estado convulsivos refratários. O certo é que ambos, em doses adequadas, quase sempre são eficazes no controle das manifestações físicas das convulsões, ressalvando-se o efeito depressor sobre o miocárdio. Caso tenha sido administrado benzodiazepínocas ou fenobarbital a dose dos barbitúricos é de $3-15 \mathrm{mg} / \mathrm{kg}$ IV (SILVA et al., 2006). Barbitúricos como: tiopental e pentobarbital têm demonstrado diminuir a pressão intracraniana depois de injúrias cerebrais devido à redução da demanda de oxigênio e glicose dos tecidos nervosos, acompanhando com isto a redução do fluxo sanguíneo cerebral devido à diminuição da pressão arterial e aumento da resistência vascular. Deve-se dar preferência ao pentobarbital ao invés do tiopental, pois o índice de mortalidade com o tiopental é maior. O coma por pentobarbital deve ser induzido com a dose inicial de $3-5 \mathrm{mg} / \mathrm{kg}$. O objetivo da terapia com barbitúricos é minimizar a atividade elétrica do encéfalo com a manutenção de adequada pressão sistêmica sanguínea (BULLOCK, 1995).

\section{Anticolinesterásicos de ação prolongada}

Os anticolinesterásicos bloqueiam a ação da enzima acetilcolinesterase (AchE), inibindo sua atividade catalítica sobre a acetilcolina (ACh) (ANDRADE, 2002; SACCO, 2006). Os agentes anticolinesterásicos são a primeira opção para o tratamento da miastenia grave (MOREIRA; MARTINS; SALGADO, 2006). Não havendo hidrólise da acetilcolina, esta se acumula nas sinapses colinérgicas, provocando estimulação desses receptores nos sistemas nervoso central e periférico (ANDRADE, 2002; SACCO, 2006). Medicamentos aticolinesterásicos de ação prolongada como brometo de piridostigmina (30-60mg, VO, q8h para cães e 2,5mg, q12h em gatos) e a neostigmina $(0,5 \mathrm{mg} / \mathrm{kg}, \mathrm{VO}, \mathrm{q} 8-12 \mathrm{~h}$ em cães) podem resultar no controle clínico da miastenia grave. Podem também ser utilizados para o diagnóstico da miastenia grave, contudo deve-se dar preferência aos anticolinesterásicos de curta ação para este fim. É difícil acertar a dose diária adequada para cada paciente, visto que o efeito médio desses fármacos varia de 1-8 h dependendo da margem de segurança juncional dos músculos afetados, a dose diverge de um animal para outro. Também o número de receptores musculares pode variar em diferentes músculos do mesmo animal doente, ou seja, uma certa dose considerada eficaz para alguns músculos pode ser exagerado ou insuficiente para outros. A piridostigmina é pouco absorvida após a administração oral, tornando necessária à administração em doses muito maiores do que quando administrada por via parenteral, sendo usadas para gatos na dose de $0,25-2 \mathrm{mg} / \mathrm{kg}$, q24h (MOREIRA; MARTINS; SALGADO, 2006). Os efeitos adversos associados são: constipação, retenção urinária e midríase (SACCO, 2006). Uma dose excessiva de anticolinesterásicos pode promover crises colinérgicas e nicotínicas ou do SNC que podem ser minimizadas com o uso de sulfato de atropina cerca de 30 minutos antes de sua administração (MOREIRA; MARTINS; SALGADO, 2006).

\section{Antifúngicos}

Ocasionalmente meningoencefalites e discoespondilites fúngicas são identificadas em pequenos animais e há poucos estudos documentando a eficácia do tratamento nessas infecções, porém a opção que se tem é avaliar os resultados documentados na medicina humana (PAPICH, 2004). Os medicamentos disponíveis são anfotericina B, flucitosina, cetoconazol, itraconazol e fluconazol. O tratamento deverá ser realizado por pelo menos seis semanas após remissão dos sinais clínicos (FENNER, 1997) e a eliminação da 
infecção fúngica do SNC em cães e gatos é difícil (LEUCOTER; CHILD, 1997).

A anfotericina B é utilizada com freqüência no tratamento das infecções fúngicas sistêmicas, embora seja fracamente absorvida no tecido nervoso. Deve-se monitorar o paciente quanto a sua nefrotoxicidade, vômito, tremores e anorexia. A dose recomendada é de $0,25 \mathrm{mg} / \mathrm{kg}$ nos primeiros dias de tratamento e posteriormente $0,5 \mathrm{mg} / \mathrm{kg}$ q24h até atingir uma dose acumulada de 4-8 mg/ $\mathrm{kg}$, sendo esta a dose total limite para ocorrência de nefrotoxicidade (PAPICH, 2004). Pode-se usar a administração intratecal de anfotericina $\mathrm{B}$, especialmente em animais com meningite por Coccidioides immitis, mas tal procedimento poderá resultar numa aracnoidite e inflamação de nervos cranianos (LEUCOTER; CHILD, 1997). A administração intratecal é efetuada com solução injetável do fármaco $5 \mathrm{mg} / \mathrm{mL}$ diluída com solução de dextrose para $0,25 \mathrm{mg} / \mathrm{mL}$, utilizando-se a dose de 0,01-0,1 mg/kg de q48-72h, sendo sua dose máxima de $0,25 \mathrm{mg}$. Este procedimento é arriscado devendo ser efetuado em último caso (PAPICH, 2004).

Combinações de medicamentos também podem ser utilizadas. A anfotericina $\mathrm{B}$, cetoconazol (má penetração no SNC) e flucitosina (boa penetração no SNC) são os principais agentes utilizados. A terapia com cetoconazol em dose elevada e por longo período foi considerada efetiva no tratamento de criptococose em gatos (LEUCOTER; CHILD, 1997).

Os imidazóis como fluconazol e itraconazol podem ser eficazes no tratamento de infecções fúngicas do SNC (LEUCOTER; CHILD, 1997). O itraconazol é altamente lipofílico e atinge altas concentrações nos tecidos. Sua concentração específica em cães e gatos ainda não foi avaliada. A dose recomendada para gatos é de $10 \mathrm{mg} / \mathrm{kg}$ q24h e para cães de $2,5-5 \mathrm{mg} / \mathrm{kg}$, q24h. Já o fluconazol (2,5-5 mg/kg, VO, q24h em cães e 2,5-10 mg/kg, VO, $\mathrm{q} 12 \mathrm{~h}$ em gatos) tem sido mais comumente utilizado no tratamento de meningoencefalite fúngica, por ter se mostrado o fármaco de maior concentração no LCE, sendo seu espectro de ação similar ao do itraconazol (PAPICH, 2004). Chrisman et al. (2005) recomenda que o tratamento antifúngico tenha no mínimo 6 semanas de duração.

\section{Antifibrinolítico}

$\mathrm{Na}$ mielopatia degenerativa tem sido relatada a utilização do ácido epsilon aminocapróico (EACA), devido a sua ação antifibrinolítica, levando a redução da inflamação associada com a degeneração de fibrina para diminuir a progressão da doença. Contudo não há estudos comprovando sua eficiência. O EACA pode causar irritação gástrica devendo ser administrado por via oral, na dose de $500 \mathrm{mg}$ q $8 \mathrm{~h}$ junto com o alimento (CHRISMAN et al., 2005).

\section{Antihistamínicos}

$\mathrm{Na}$ chamada síndrome vestibular idiopática ocasionalmente ocorrem vômitos. Nestas situações podem ser usados a difenidramina, $2-4 \mathrm{mg} / \mathrm{kg} \mathrm{SC}$, $\mathrm{q} 8 \mathrm{~h}$, ou fármacos vestibulo-sedativos como a meclisina 1-2 mg/kg VO, q24h para alívio da êmese associada à cinetose (TAYLOR, 2006). Meclisina pode ser usada também em casos de náusea. Nas primeiras 24-48 horas pode-se administrar cloridrato de meclizina oral $6,25 \mathrm{mg}$, q24h para gatos e 12-25mg, q24h para cães para reduzir a tontura e o desconforto do paciente. O diazepam 0,1$0,25 \mathrm{mg} / \mathrm{kg}, \mathrm{VO}, \mathrm{q} 8 \mathrm{~h}$, pode ser usado para reduzir o desconforto se a meclisina não estiver disponível, mas pode causar alguma sedação (CHRISMAN et al., 2005).

\section{Antiinflamatórios}

Os efeitos da inflamação no sistema nervoso são edema, necrose, vasculite, hipóxia e efeitos tóxicos diretos dos neutrófilos sobre SNC (FENNER, 1997). Durante a hipóxia, os radicais livres de oxigênio são gerados a partir da síntese de prostaglandinas onde 
a reintrodução de oxigênio nos tecidos isquêmicos, resulta na produção em massa de radicais livres, configurando a chamada lesão da reperfusão, causando morte neuronal (SACCO, 2006).

\section{Antiinflamatórios não-esteróides (AINES)}

Os AINES são apropriados para o tratamento da inflamação associada a certas enfermidades, quando a terapia por corticosteróides tiver o potencial de causar demasiada quantidade de efeitos colaterais (MCDONALD; LANGSTON, 1997). A associação de AINES a corticosteróides é um risco, uma vez que pode acarretar em úlceras gastrintestinais e hemorragias e é absolutamente contra-indicada (PAPICH, 2004). Não apenas os corticosteróides prejudicam o sistema imune do paciente, mas também normaliza a BHE, o que diminui a capacidade de penetração dos antibióticos no SNC. Nestes casos, medicamentos antiinflamatórios nãoesteróides podem ser benéficos (FENNER, 1997).

As principais ações farmacológicas dos AINES são antiinflamatórias e analgésicas. As ações antiinflamatória e analgésica ocorrem pela inibição da COX-1 e COX-2, em proporções geralmente diferentes, inibindo a liberação de prostaglandinas e tromboxanos, importantes mediadores da inflamação e da dor. A ação antipirética é por causa da inibição da $\mathrm{PGE}_{2}$ liberada após a ação fagocitária dos leucócitos sobre partículas estranhas, liberando pirógenos endógenos. Possui também ação anticoagulante, por inibição da síntese de tromboxanos, que aumenta a agregação plaquetária, e ação antiespasmódica por diminuição da liberação de prostaglandinas ao nível do endométrio (ANDRADE, 2002).

A aspirina é administrada oralmente a todas as espécies e pode controlar a febre, a dor somática leve a moderada e alguns estados antiinflamatórios. Doses de $10 \mathrm{mg} / \mathrm{kg}, \mathrm{q} 12 \mathrm{~h}$, VO são geralmente suficientes para a maioria dos cães, para o controle da febre e da dor, enquanto 20-30 mg/kg, VO, q12h seriam necessário para o tratamento da inflamação (MCDONALD; LANGSTON, 1997). Estudos mostram que aspirina $25 \mathrm{mg} / \mathrm{kg} \mathrm{VO}$ q3dias durante toda a vida do paciente é medicação profilática em neuromiopatia isquêmica em gatos (MCDONALD; LANGSTON, 1997). Deve-se tomar cuidado com os seus efeitos gastrintestinais e renais adversos, não devendo ser combinados com corticosteróides (BAGLEY, 2005). No tratamento da neuromiopatia isquêmica tem sido associada à aspirina, warfarina e heparina, objetivando a redução das chances de recidiva do tromboembolismo (CHRISMAN et al., 2005).

Nas afecções espinhais utiliza-se principalmente o carprofeno (2,2 mg/kg, VO, q12h ou 4,4 mg/ $\mathrm{kg}, \mathrm{VO}, \mathrm{q} 24 \mathrm{~h})$ e o endolac $(10-15 \mathrm{mg} / \mathrm{kg}, \mathrm{q} 24 \mathrm{~h})$ (BAGLEY, 2005). Na espondilose deformante e estenose lombossacra é indicado o uso de AINES como carprofeno (2,2 mg/kg, q12h), meloxicam $(0,1 \mathrm{mg} / \mathrm{kg}, \mathrm{q} 24 \mathrm{~h})$ ou cetoprofeno (1-2 mg/kg, q24h) (PELLEGRINO, 2003).

\section{Corticosteróides}

As doenças neurológicas freqüentemente requerem terapia com corticosteróides (PLATT, 2002), sendo estes comumente prescritos em animais com doença espinhal devido a sua ação antiinflamatória e redução do edema. São mais efetivos em doenças neoplásicas ou inflamatórias do que infecciosas. $\mathrm{O}$ uso de corticosteróides no tratamento do trauma espinhal é comum, porém não é aceito mundialmente e o seu uso em doenças do disco intervertebral é polêmico. Os efeitos adversos do uso de corticosteróides, principalmente quando usados em altas doses e em tratamentos de longa duração são os efeitos gastrintestinais (úlceras) e imunossupressivos, também podendo aumentar a incidência de pancreatite (BAGLEY, 2005). Além destes, a terapia com corticosteróides em longo prazo pode causar também hepatopatias e miopatias (CHRISMAN et al., 2005). A dexametasona pode causar complicações gastrintestinais mais severas quando comparada a prednisona e metilprednisona (THOMAS, 2002). 
Pode-se fazer uso dos corticosteróides de duas formas distintas: em doses antiinflamatórias podese utilizar a dexametasona na dose de $0,15 \mathrm{mg} / \mathrm{kg}$ ou a prednisona na dose de $1 \mathrm{mg} / \mathrm{kg}$ ou em doses imunossupressivas no tratamento de afecções imunomediadas que ocorrem no SNC e sistema nervoso periférico (SNP), incluindo a meningite responsiva ao corticóide, miastenia grave, miosite mastigatória, polimiosite e meningoencefalomielite granulomatosa (MEG). A dose imunossupressiva de prednisona é 2-4 mg/kg q24h. Para terapêutica imunossupressiva pode-se usar a azatioprina na dose de 2mg/kg, q24h (PAPICH, 2004).

Osefeitos benéficosdaterapiacomcorticosteróides referem em particular a doenças do encéfalo e da medula espinhal, incluindo a proteção contra radicais livres, reduzindo a pressão intracraniana ao diminuir a produção do LCE e mantendo a integridade vascular (PLATT; ABRAMSON; CAROSI, 2005). Visto que muitos sinais clínicos nos casos de encefalite estão relacionados à inflamação, e não a algum microrganismo, mesmo pacientes com infecções podem ser inicialmente tratados com corticosteróides (FENNER, 1997). Os efeitos dos corticosteróides no SNC estão bem documentados. Indiretamente eles mantêm a concentração plasmática de glicose, responsável pela função cerebral, manutenção do fluxo cerebral e influencia no balanço eletrolítico do SNC (PLATT; ABRAMSON; GAROSI, 2005). Reduzem o edema estabilizando as membranas celulares a BHE, evitando o desenvolvimento de mais edema. Dentre as três formas de edema cerebral, os corticosteróides são bastante eficientes para dois, o edema vasogênico, causado por inflamações e tumores, e o intersticial, causado por hidrocefalia na região periventricular. Os corticosteróides também modulam a resposta inflamatória que resulta em necrose tecidual, diminuindo a desmielinização secundária ocorrente de 1-5 dias após o trauma craniocerebral (FENNER, 1997; PLATT; ABRAMSON; GAROSI, 2005).

Os corticosteróides também podem aliviar o edema subseqüente a traumas no SNC, desde que sejam administrados em alta dosagem e dentro das primeiras 8h do traumatismo (FENNER, 1997). Existem evidências de melhora após administração de succinato de metilprednisolona em pacientes veterinários com severo trauma craniano, porém rotineiramente a administração de corticosteróides não é recomendada. A administração de corticosteróides em pacientes com trauma craniano é controversa (DEWEY; BUDSBERG; OLIVER, 1993). No passado foram utilizados protocolos para pacientes após 1 hora do trauma crânio-encefálico onde era administrado metilprednisolona $(30 \mathrm{mg} /$ $\mathrm{kg}$ ) em injeção intravenosa rápida concentrada; em seguida, repetia-se esta injeção em 2-6 h (FENNER, 1997), contudo a literatura atual, principalmente sobre o traumatismo crânio-encefálico em humanos, não recomenda o uso rotineiro de corticosteróides (GHAJAR; HESDORFFER, 2004)

Em pacientes com injúrias parciais da medula com menos de $8 \mathrm{~h}$ de evolução tem sido demonstrado bom resultado com a administração de succinato de metilprednisolona. A dose inicial é de $30 \mathrm{mg} / \mathrm{kg}$, IV com doses adicionais de $15 \mathrm{mg} / \mathrm{kg}$ de $2-6 \mathrm{~h}$ depois da dose inicial e depois q8h até completar $48 \mathrm{~h}$ de tratamento depois do trauma (PLATT;ABRAMSON; GAROSI, 2005). Contudo este protocolo também tem sido questionado recentemente.

A dexametasona e a prednisona têm sido freqüentemente utilizadas com doses antiinflamatórias em resposta a extrusão de disco reduzindo o edema e melhorando o fluxo da medula espinhal. Deve-se tomar cuidado com o uso dos corticosteróides, pois eles podem diminuir o desconforto dos pacientes com doenças espinhais, encorajando-os à atividade excessiva (PLATT; ABRAMSON; GAROSI, 2005). O protocolo utilizado na discopatia intervertebral degenerativa é de $0,25-1 \mathrm{mg} / \mathrm{kg}$ de prednisona, VO, q12h, com doses reduzidas por 30 dias. Nos casos de espondilomielopatia cervical ou síndrome de wobbler, cães levemente afetados podem melhorar com $0,25 \mathrm{mg} / \mathrm{kg}$ de prednisona, VO, $\mathrm{q} 12 \mathrm{~h}$ (CHRISMAN et al., 2005) 
Os corticosteróides são recomendados também nos casos de meningite imuno-mediada em doses imunossupressivas, e podem ser usados nos casos de meningoencefalites bacterianas por curto período. Os corticosteróides podem diminuir a inflamação, e assim diminuir as lesões resultantes à medula espinhal; todavia, este tratamento também poderá deprimir os mecanismos de defesa do hospedeiro, e às vezes poderá resultar numa deterioração dos sinais clínicos, e numa incidência mais elevada de recidivas (LEUCOTER; CHILD, 1997). Nas doenças bacterianas utiliza-se $0,15 \mathrm{mg} / \mathrm{kg}$ de dexametasona 15-20 minutos antes do início da terapia antimicrobiana (PLATT; ABRAMSON; CAROSI, 2005). O protocolo para o tratamento de meningite imunomediada em longo prazo com prednisona é $2 \mathrm{mg} / \mathrm{kg}$, VO, q12h por dois dias, posteriormente redução para $1 \mathrm{mg} / \mathrm{kg}$, q12h, por mais duas semanas e depois $0,5 \mathrm{mg} / \mathrm{kg}$, q12h por um mês. Finalmente terapia por dias alternados durante 4-20 meses (CHRISMAN et al., 2005).

Nos casos de cinomose, erliquia, toxoplasmose e neosporose utiliza-se a dose de $1-2 \mathrm{mg} / \mathrm{kg}$, IV de dexametasona. Nos casos de encefalomielite por peritonite infecciosa felina utiliza-se doses imunossupressivas e doses antiinflamatórias incluindo prednisona (2-4 mg/kg, VO, q24h) (BRAUND, 1997). Os corticosteróides podem ser eficazes na meningite imunomediada associada à erliquiose, e tratamentos curtos de 2-7 dias podem ser benéficos em caso de erliquiose com trombocitopenia concomitante (PLATT, 2002). No tratamento de rotina da MEG utiliza-se também medicamentos imunossupressivos. O medicamento usado com maior freqüência é a prednisona 1-2 mg/ kg, q24h, entretanto, também estão sob consideração outros medicamentos como a azatioprina (FENNER, 1997). Em casos de MEG deve-se utilizar 1-2 mg/ $\mathrm{kg}$ de prednisona $\mathrm{VO}, \mathrm{q} 12 \mathrm{~h}$, porém o prognóstico é ruim e a resposta variável (PLATT, 2002).

Não há dados que relatem a sobrevivência de cães e gatos com neoplasias cerebrais utilizando apenas corticosteróides, sendo considerado como tratamento paliativo, também há poucos relatos sobre avaliação do uso corticosteróides em pacientes com tumores espinhais, porém é claramente indicado o seu uso em compressões de raízes nervosas (PLATT; ABRAMSON; CAROSI, 2005). Em alguns casos de neoplasias cerebrais, a prednisona $(0,25-0,5$ $\mathrm{mg} / \mathrm{kg}, \mathrm{VO}, \mathrm{q} 12 \mathrm{~h}$ ) pode reduzir o edema cerebral secundário e aliviar os sinais clínicos por vários meses (CHRISMAN et al., 2005).

Pode-se lançar mão de corticosteróides, tanto na hidrocefalia primária, quanto na secundária, (FENNER, 1997). Na hidrocefalia o uso de corticosteróides pode diminuir o liquido cerebroespinhal, pressão intracraniana e diminuir injúrias neurológicas. Recomenda-se a utilização de prednisona $0,25-0,5 \mathrm{mg} / \mathrm{kg}$, VO, q6h. A dose pode ser reduzida depois de 2-4 meses (BRAUND, 1997). É sugerido por alguns autores o uso de prednisona 0,25-0,5 mg/kg, VO, q12h, nos casos de hidrocefalia (DEWEY, 2003). Alternativamente pode-se utilizar a dexametasona $0,25 \mathrm{mg} / \mathrm{kg}, \mathrm{VO}, \mathrm{q} 6-8 \mathrm{~h}$ sendo a dose reduzida 2-4 semanas (PLATT, 2002).

Nos casos de neurite óptica o animal poderá ser tratado sintomaticamente, por meio de corticosteróides retrobulbares (ex. betametasona 2,5mg), juntamente com a administração de prednisona $1 \mathrm{mg} / \mathrm{kg}$, VO, q12h durante 10-14 dias. Seguida por metade da dose por mais duas semanas e com redução gradual até terapia de manutenção em dias alternados durante um ano (BRAUND, 1997). Na neurite óptica idiopática é sugerido o uso de 2 $\mathrm{mg} / \mathrm{kg}$, q12h durante 14 dias e redução gradual após esse período (TILLEY; SMITH JUNIOR, 2003).

No acidente vascular cerebral a administração de corticosteróides não tem um efeito positivo, podendo alterar o tamanho do infarto ou hemorragia, mas provavelmente não reduzindo a pressão intracraniana, sendo o benefício da utilização nessa afecção questionável (PLATT, 2002). O tratamento para distúrbios cerebrovasculares deve ser ajustado para tratar a doença subjacente, se houver uma, como por exemplo, em animais que apresentam 
migração parasitária usa-se prednisona 0,25$0,5 \mathrm{mg} / \mathrm{kg}, \mathrm{VO}, \mathrm{q} 12 \mathrm{~h}$ por 3 a 5 dias, com redução subseqüente (CHRISMAN et al., 2005). Atualmente tem sido demonstrado que o uso de corticosteróides na presença de isquemia é perigoso, sendo relatado o fato de que com os corticosteróides os animais são mais vulneráveis a isquemia-hipóxia cerebral (PLATT; ABRAMSON; CAROSI, 2005).

Dentre as doenças imunomediadas neuromusculares a miastenia gravis pode ser tratada com doses imunossupressivas de prednisona 2-4 mg/ $\mathrm{kg}$ durante duas semanas, reduzindo gradativamente a dose. Pode-se também iniciar com uma dose menor de prednisona $(0,25 \mathrm{mg} / \mathrm{kg}$ q12-24h) e depois ir gradativamente aumentando ao longo de algumas semanas para impedir a deterioração clínica (SHELTON, 2002). Já nos casos de polimiosite idiopática e na miosite dos músculos mastigatórios deve-se administrar de 1-2 mg/kg, VO, q12h durante 2 e 3 semanas respectivamente com redução gradativa por alguns meses até fazer a retirada total do medicamento (PLATT, 2002).

\section{Antineoplásicos}

A quimioterapia antineoplásica tem sido tradicionalmente inefetiva nos casos de tumores cerebrais em cães e gatos, pois os fármacos têm pobre penetração na barreira hematoencefálica, porém a carmustina (BCNU) e a lomustina (CCNU) vêm sendo utilizados nos casos de gliomas em cães (DEWEY, 2003). Embora existam casos selecionados em que a quimioterapia foi benéfica, este procedimento não se mostrou tão promissor quanto à radiação ou a cirurgia. Concomitantemente com o tratamento do tumor, procede-se ao tratamento dos efeitos secundários, como o edema (FENNER, 1997). A lomustina oral retarda o crescimento tumoral e pode ser uma opção para alguns animais. Administra-se $60 \mathrm{mg} / \mathrm{m}^{2}$, VO, e se realiza hemograma e contagem plaquetária toda semana por 5 semanas. Se a contagem plaquetária for de 50.000 células por $\mu \mathrm{L}$ ou acima disso e as plaquetas estiverem na variação normal, então se deve aumentar a dose de lomustina para $80 \mathrm{mg} / \mathrm{m}^{2}$ (CHRISMAN et al., 2005).

Nos casos de MEG confirmada pelo exame histológico de biópsia cerebral, pode-se administrar o fármaco antineoplásico procarbazina, 2-4 mg/ $\mathrm{kg}, \mathrm{VO}, \mathrm{q} 24 \mathrm{~h}$, por 1 semana e depois aumentar para 4-6 mg/kg, q24h, devendo-se monitorar o número de plaquetas e leucócitos, já que a duração do tratamento é de 6-12 meses para controle dos sinais clínicos (CHRISMAN et al., 2005). Segundo Coates, Barone e Dewey (2007) o tratamento com procarbazina pode resultar em aumento da sobrevida do paciente e pode ser complementado com outras terapias imunossupressoras. Pode-se fazer uso de citosina arabinosídeo em casos de MEG, como agente isolado ou em combinação com a prednisona, na dose de $50 \mathrm{mg} / \mathrm{m}^{2}$, SC, q12h por 2 dias consecutivos, repetindo o esquema a cada três semanas (LORENZ; KORNEGAY, 2006), sendo relatado que o uso de prednisona e citosina arabinosídeo pode ser um tratamento empírico seguro em pacientes com meningoencefalite de etiologia desconhecida, podendo prolongar o tempo de vida desses animais (ZARFOSS et al., 2006). Já Taylor (2006) relata que raras às vezes a terapia com citosina arabinosídeo $\left(50 \mathrm{mg} / \mathrm{m}^{2}, \mathrm{SC}\right.$ ou IV, q24h durante 2 dias, seguido por $100 \mathrm{mg} / \mathrm{m}^{2} 1 \mathrm{vez}$ por semana) é eficaz. Segundo Gnirs (2006) o uso da ciclosporina $10 \mathrm{mg} / \mathrm{kg}$, VO, q24h durante seis semanas, posteriormente reduzindo para $5 \mathrm{mg} / \mathrm{kg}$, VO, q24h, teve melhoria satisfatória nos sinais clínicos, onde seis semanas após o início do tratamento com ciclosporina os resultados clínicos foram similares aos obtidos com o uso da prednisona.

\section{Antipsicóticos}

Os antipsicóticos também chamados de neurolépticos ou tranqüilizantes maiores, são classificados em alta potência e baixa potência, os primeiros são isentos de efeitos colaterais, como xerostomia e hipotensão postural e menos sedativos 
que os segundo, como a clorpromazina. As maioria dos antipsicóticos são bem absorvidos no trato gastrintestinal, mas a disponibilidade sistêmica é baixa porque sofrem intenso metabolismo e extração hepática de primeira passagem. De modo geral alcançam concentrações máximas 2-3 h após dose oral única (MORAIS; OLIVEIRA, 2006).

Os efeitos sedação, colinérgicos e bloqueio alfaadrenérgico (hipotensão) dos antipsicóticos nos animais domésticos são eventualmente utilizadas no tratamento de certos casos de ansiedade (ANDRADE, 2002). Esse procedimento deve, no entanto ser evitado, uma vez que os ansiolíticos benzodiazepínicos são mais seguros a esse propósito (PLATT; ABRAMSON; CAROSI, 2005). Pode-se fazer uso da clorpromazina no tratamento de distúrbios como: ansiedade, no comportamento dimórfico masculino (monta e marcação de território), agressão pelo temor, comportamento tímido, obsessivo, compulsivo e/ou automultilação (LIS, 2003). As doses sugeridas para a clorpromazina nos casos de distúrbio de comportamento em cães e gatos é de 0,5-3,3 mg/kg, VO, q6-24h como sedativo utiliza-se à dose de $0,5 \mathrm{mg} / \mathrm{kg}$, IM ou IV; e para a acepromazina em cães $0,1-0,25 \mathrm{mg} / \mathrm{kg}$, IM ou VO e em gatos 1,1-2,2 mg, VO ou 0,11-0,22mg/kg, IM ou SC (ANDRADE, 2002).

\section{Ansiolíticos}

Os ansiolíticos utilizados no combate aos sinais causados pela ansiedade são os benzodiazepínicos (diazepam, alprazolam e clorazepato) e as azapironas (buspirona) (SILVEIRA, 2006). Os benzodiazepínicos causam redução da ansiedade e da agressividade, sedação, relaxamento muscular e supressão das convulsões, sendo indicado no tratamento de distúrbios de ansiedade, na síndrome da ansiedade da separação (medicar pelo menos uma hora antes de o proprietário sair de casa), distúrbios compulsivos e marcação excessiva urinária pelos gatos (ANDRADE, 2002). O flumazenil é o fármaco empregado, como antagonista eficaz, no tratamento de intoxicações especificamente causadas pelos benzodiazepínicos (SILVEIRA, 2006). A dose para cães de diazepam para distúrbios de ansiedade é de $0,55-2,2 \mathrm{mg} / \mathrm{kg}, \mathrm{VO}, \mathrm{q} 12 \mathrm{~h}$ e para gatos $1-2 \mathrm{mg}$ total, VO, q12h (ANDRADE, 2002; LIS, 2003).

Após o reconhecimento do que o ácido gamaaminobutírico (GABA) é um dos mediadores centrais mais importantes relacionados ao efeito depressor e ao mecanismo de ação dos benzodiazepínicos, alguns países o introduziram na terapêutica como ansiolíticos. Tem baixa lipofilicidade e, portanto, dificuldade de atravessar a barreira hematoencefálica (SILVEIRA, 2006).

Geralmente, os efeitos ansiolíticos da buspirona levam dias ou semanas para manifestar-se e os efeitos colaterais são menos incômodos do que aqueles observados com o uso dos benzodiazepínicos. As indicações nos distúrbios de comportamento são iguais aos indicados para os benzodiazepínicos, com a vantagem de serem mais seguros e mais bem tolerados, com a desvantagem de necessitarem de doses diárias mais freqüentes. A dose da buspirona utiliza-se $1-2,1 \mathrm{mg} / \mathrm{kg}$, VO, q8h e em gatos $0,5-1$ $\mathrm{mg} / \mathrm{kg}, \mathrm{VO}, \mathrm{q} 8 \mathrm{~h}$ para distúrbios de comportamento e 2,5-5mg total, VO, q8h para marcação excessiva urinária com duração de tratamento de 6-8 semanas (ANDRADE, 2002, LIS, 2003).

\section{Antidepressivos}

Os antidepressivos tricíclicos estão inclusos entre os fármacos mais eficazes no controle da dor cônica, incluindo a neuropática. Eles exercem ação sedativa, ansiolítica, miorrelaxante e antiinflamatória, além de regularizar o sono e melhorar o apetite (MOREIRA, 2005). O cloridrato de selegilina, $0,5-1 \mathrm{mg} / \mathrm{kg}, \mathrm{VO}$, q24h pela manhã, pode melhorar a atividade mental sendo utilizado nos casos de síndrome de disfunção cognitiva em cães. A dose não deve exceder $2 \mathrm{mg} / \mathrm{kg}$, q24h e não deve ser usada intercorrentemente com antidepressivos tricíclicos (como clomipramina, amitriptilina e imipramina) ou bloqueadores de recaptação de serotonina como fluoxetina, pois 
podem ocorrer efeitos tóxicos e morte (DEWEY, 2003; CHRISMAN et al., 2005). Pode-se utilizar antidepressivos nos casos de agressão por domínio, ansiedade por separação, comportamento dimórfico masculino, comportamento tímido ou agressão pelo temor e distúrbios obsessivo-compulsivos, sendo as medicações mais utilizadas a amitriptilina $0,5 \mathrm{mg} /$ $\mathrm{kg}, \mathrm{VO}, \mathrm{q} 8-12 \mathrm{~h}$ e a fluoxetina $0,5 \mathrm{mg} / \mathrm{kg}, \mathrm{VO}, \mathrm{q} 8-$ $12 \mathrm{~h}$ nos gatos e $1 \mathrm{mg} / \mathrm{kg}, \mathrm{VO}, \mathrm{q} 24 \mathrm{~h}$ nos cães com duração do tratamento de 6-8 semanas para ambos (MORAIS; OLIVEIRA, 2006).

No tratamento da narcolepsia são utilizados principalmente os antidepressivos tricíclicos como imipramina 0,4-1 mg/kg, VO q8-12h, protripilina 5-10 mg, VO, q24h, amitriptilina $1-2 \mathrm{mg} / \mathrm{kg}, \mathrm{VO}$, $\mathrm{q} 12 \mathrm{~h}$ e fluxetina $1 \mathrm{mg} / \mathrm{kg}, \mathrm{VO}, \mathrm{q} 24 \mathrm{~h}$ nos casos de catalepsia. Quando o animal apresenta além de catalepsia o sono excessivo utilizam-se os simpatomiméticos metilfenidato $0,25 \mathrm{mg} / \mathrm{kg}, \mathrm{VO}$, q8-12h ou dextroanfetamina 5-10mg, VO, 8-12h e em apenas sono excessivo utiliza-se a selegilina 1 $\mathrm{mg} / \mathrm{kg}$, VO, q24h (THOMAS, 2003).

\section{Antioxidantes e varredores de radicais livres}

Os antioxidantes atuam fornecendo hidrogênio para o radical livre e o estabilizando. O antioxidante torna-se um radical livre, mas tem a propriedade de poder reajustar-se em um composto estável e dessa maneira interromper a reação de propagação em cadeia (LIS, 2003).

Há grandes evidências de que a produção de radicais livres afeta o sistema nervoso após o trauma craniano, contribuindo para a autólise e o edema cerebral. O radical superóxido tem sido demonstrado após $1 \mathrm{~h}$ da injúria cerebral experimental em gatos. $\mathrm{O}$ mesilato de deferoxamina é importante antioxidante tendo dose recomendada de $25-50 \mathrm{mg} / \mathrm{kg}$, IM ou IV (lentamente) (THOMAS, 2003).

Os lazaróides ou 21-aminocorticosteróides são análogos à metilprednisolona, porém não ativam os receptores corticosteróides, além de ter efeitos antioxidantes (DEWEY, 2003). São 100 vezes mais potentes do que o succinato sódico de metilprednisolona na inibição da peroxidase lipídica. O tirilazade é um 21-aminoesteróide desenvolvido para uso clinico (BERGMAN; LANZ; SHELL, 2000). Porém em pesquisa, onde o aminocorticosteróideU74389G foiusadonadosagem de $30,15,10,5$ e $1,5 \mathrm{mg} / \mathrm{kg} \mathrm{IV}$, não foi observado melhora na recuperação neurológica dos animais, quando comparados ao grupo controle (COATES et al., 1995). Isto sustenta a idéia de que os benefícios obtidos com o uso do tirilazade não são comparados com os observados com a administração de succinato sódico de metilprednisolona (SILVEIRA, 2006).

Alopurinol, mesilato de deferoxamina e DMSO podem ser usados no tratamento dos traumas craniano e medular agudos (DEWEY, 2003). A $\mathrm{N}$-acetilcisteína (NAC) é um antioxidante potente que impede a destruição tecidual induzida por radicais livres, sendo utilizado na mielopatia degenerativa na dose de $25 \mathrm{mg} / \mathrm{kg}$, q8h por duas semanas e posteriormente em dias alternados por mais duas semanas, tendo como objetivo a redução da progressão da doença (CHRISMAN et al., 2005).

O DMSO tem o potencial de reduzir a magnitude da necrose tecidual após lesão medular, protegendo a medula espinhal contra efeitos deletérios dos radicais livres induzidos pela peroxidação (EWAN, 1996). Estudos de microscopia eletrônica indicam que o DMSO, administrado uma hora após a lesão contusiva em cães, protegeu a bainha de mielina e axônios, reduzindo o edema e acelerando o retorno à função motora (BERGMAN; LANZ; SHELL, 2000). No entanto, em outro estudo realizado com gatos submetidos a trauma medular agudo, não se observou diferença significativa da eficácia do DMSO entre os grupos de animais tratados e não tratados (COATES et al., 1995). Adose recomendada no tratamento do edema ou traumatismo do SNC é de $0,5-1 \mathrm{~g} / \mathrm{kg}, \mathrm{IV}$, q24h, lentamente com solução a 10\% (MCDONALD; LANGSTON, 1997). 
O DMSO tem sido efetivo na redução da pressão intracraniana no trauma craniano, pois tem efeito neuroprotetor, reduzindo a oxigenação e requerimento de glicose pelo tecido cerebral, além da diminuição do edema devido a suas propriedades antiinflamatórias e diuréticas (BULLOCK, 1995).

\section{Diuréticos}

Os diuréticos reduzem a pressão intracraniana (PIC), tanto pela remoção do edema, quanto pela redução do volume intracraniano. $\mathrm{O}$ manitol é um diurético osmótico comumente utilizado na redução da PIC elevada e é exclusivamente administrado pela via intravenosa. Ele é totalmente excretado através da filtração glomerular, não sofre metabolização, nem mesmo reabsorção tubular e é eliminado através da urina. Sua principal indicação é diminuição do edema cerebral principalmente no sentido de manter um gradiente osmótico, além de apresentar capacidade de reperfusão e mobilização de radicais livres (BULLOCK, 1995; FRANKLIN, 1995). A dose é de $1 \mathrm{~g} / \mathrm{kg}$, IV, q6-8h (SPINOSA; GORNIAK; BERNARD, 1999). A dose recomendada nos casos de trauma craniano é de 0,25-2 g/kg IV, lentamente (duração entre $20 \mathrm{e}$ 30 minutos), administrado IV como solução a $20 \%$, sendo aplicado na velocidade de $2 \mathrm{~mL} / \mathrm{kg} /$ minuto (BULLOCK, 1995; FRANKLIN, 1995).

A colheita de fluido cerebroespinhal espinhal é arriscada quando associada à elevação da pressão intracraniana, pois pode ocorrer herniação cerebral. Nestas situações pode-se fazer uso do manitol na dose em bolos de 0,25-2 g/kg, IV durante 10-15 minutos, seguido em 15 minutos por furosemida $(0,7 \mathrm{mg} / \mathrm{kg})$ antes da coleta de fluido cerebroespinhal (CHRISMAN et al., 2005).

A furosemida aparentemente diminui a produção do LCE e facilita a reabsorção do edema cerebral, diminuindo o volume intracraniano, podendo ser utilizada na dose de $0,7 \mathrm{mg} / \mathrm{kg}$, administrada em forma de injeção intravenosa concentrada, que deverá ser repetida em $4 \mathrm{~h}$. Se a furosemida é administrada juntamente com manitol, os efeitos destes dois medicamentos ficarão potencializados, ficando reduzidos os edemas de rebote, sugerindose a administração da furosemida juntamente ao manitol no trauma craniano, pois a furosemida previne a expansão rápida de volume, diminui o risco de edema pulmonar e promove rápida excreção do manitol pelos rins (FRANKLIN, 1995; FENNER, 1997; THOMAS, 2003).

Acetozolamida pode ser usado para diminuir a produção de líquido cerebroespinhal utilizando-se na dose de $10 \mathrm{mg} / \mathrm{kg}$, VO, q 6-8h, assim como a metazolamida nos casos de hidrocefalia (DEWEY; BUDSBERG; OLIVER, 1993).

\section{Fármacos que atuam na função da micção}

A disfunção no armazenamento da urina pela bexiga se dá pela hiperreflexia do músculo detrusor que ocorre devido a distúrbios cerebelares e doenças da medula espinhal crônicas. Os fármacos utilizados nestes casos são: brometo de propantelina 0,25-0,5 $\mathrm{mg} / \mathrm{kg}, \mathrm{VO}, \mathrm{q} 8 \mathrm{~h}$ ou cloridrato de oxibutinina $2-5 \mathrm{mg}$, VO, q8-12h (COATES, 2004).

A incontinência uretral está associada a lesões na região medular sacral e tem como tratamentos: a administração do fenilpropanolamina $1,5 \mathrm{mg} / \mathrm{kg}$, VO, q8-12h que tem como efeitos adversos a retenção urinária e a taquicardia, ou a imipramina $5-15 \mathrm{mg}$, VO, q12h tendo como efeitos adversos convulsões, tremores e hiperexcitabilidade (COATES, 2004).

A incapacidade de urinar se dá pela ausência ou incompleta contração da bexiga ou obstrução uretral (anatômica ou funcional). A ausência ou incompleta contração da bexiga está associada às lesões craniais à L7 (neurônio motor superior) sendo uma seqüela comum nos casos de mielopatia entre T3-L3, onde as vias motoras e sensitivas do reflexo detrusor estão afetadas. Também pode ocorrer nos casos de lesões medulares, sacrais, raízes nervosas e/ou plexo pélvico (COATES, 2004). A atonia da bexiga se dá quando esta se distende além de 
sua capacidade máxima. As obstruções urinárias podem ser devido a causas neurogênicas ou não neurogênicas. Na neurogênica é indicado o uso de fármacos que diminuem a resistência do esfíncter interno que é composto por fibras musculares lisas que mantém o tônus muscular através de impulsos simpáticos do nervo hipogástrico. Lesões na cauda eqüina podem ser associadas à incoordenação do esfíncter e conseqüentemente retenção urinária (FISCHER; LANE., 2003). O objetivo do tratamento é diminuir a resistência da musculatura lisa com a administração de fármacos que promovam o relaxamento da uretra. Os fármacos empregados são: a fenoxibenzamina $0,25-0,5 \mathrm{mg} / \mathrm{kg}, \mathrm{VO}, \mathrm{q} 12-$ 24h (COATES, 2004), cujos efeitos adversos são hipotensão e taquicardia e o prazosin $1 \mathrm{mg} / 15 \mathrm{~kg}$, VO, q12-24h em cães e 0,25-0,5 mg, VO, q12$24 \mathrm{~h}$ em gatos, cujos efeitos adversos relatados são: hipotensão, taquicardia, sedação e ptialismo (FISCHER; LANE, 2003; COATES, 2004). O diazepam é comumente adicionado ao tratamento com o propósito de relaxamento na musculatura esquelética na dose de $1-25 \mathrm{mg}$, VO, q8h em gatos e 2-10mg, VO, q6h em cães, outros benzodiazepínicos como o alprazolan podem ser uma alternativa, quando o diazepam tiver que ser utilizado por longos períodos, porém seu efeito na musculatura uretral ainda não foi estudada (FISCHER; LANE, 2003). Outros relaxante muscular esqueléticos utilizados adicionalmente para promover o relaxamento uretral são dantrolene $(0,5-2 \mathrm{mg} / \mathrm{kg}, \mathrm{VO}, \mathrm{q} 8 \mathrm{~h}) \mathrm{e}$ metocarbamol (inicialmente $66 \mathrm{mg} / \mathrm{kg}, \mathrm{VO}, \mathrm{q} 12 \mathrm{~g}$ e posteriormente $33 \mathrm{mg} / \mathrm{kg}$, VO, q12h).

Nos casos de atonia ou hipotonia do detrusor o tratamento preconizado é o uso de betanecol 1,25$5 \mathrm{mg}$, VO, q8h em gatos e 2,5-25mg, VO, q8h em cães ou 2,5-10mg, SC, q8h em cães sendo seus efeitos adversos vômito, diarréia, hipersalivação, hipotensão, dispnéia e bradicardia. A cisaprida $(0,5 \mathrm{mg} / \mathrm{kg}, \mathrm{VO}, \mathrm{q} 8 \mathrm{~h}$, ) e o propanolol (2,5mg, VO, q8-12h) também podem ser utilizados (FISCHER; LANE, 2003).

$\mathrm{Na}$ disautonomia a administração de fármacos parassimpatomiméticas como cloridrato de betanecol 5-25 mg, VO, q8h em cães e 2,5-5mg, VO, q8-12h em gatos pode aliviar alguns sintomas. Uma ou duas gotas de preparações oftálmicas de fisostigmina a $0,5 \%$ ou pilocarpina a $1 \%$ em ambos os olhos pode ter alguns efeitos sistêmicos (CHRISMAN et al., 2005).

\section{Fitoterápicos}

O extrato padronizado de Ginkgo biloba, 2-4 mg/ $\mathrm{kg}, \mathrm{VO}, \mathrm{q} 8-12 \mathrm{~h}$, constitui uma preparação de ervas que aumenta o fluxo sangüíneo cerebral, podendo também ser útil na síndrome da disfunção cognitiva (CHRISMAN et al., 2005).

\section{Modificadores do metabolismo articular (nutracêuticos)}

Glicosamina e sulfato de condroitina podem ser usados na espondilose deformante e estenose lombossacra (DEWEY, 2003; PELLEGRINO, 2003).

\section{Relaxantes musculares}

O aumento do tônus muscular é a principal característica de muitas doenças que atingem o SNC. O tônus muscular aumentado provoca incapacitação e dor. Os relaxantes musculares são divididos em relaxantes musculares de ação central (miorrelaxantes) e relaxantes musculares de ação periférica (bloqueadores neuromusculares). Os de ação central são fármacos utilizados no tratamento de episódios agudos de espasticidade, associadas a vários distúrbios músculo-esqueléticos e neurológicos (ANDRADE, 2002).

A ação miorrelaxante dos benzodiazepínicos é resultado de sua capacidade em promover inibição pré-sináptica mediada pelo GABA no SNC e em deprimir neurônios no sistema reticular lateral descendente (SACCO, 2006). Os mais utilizados deste grupo são: o diazepam na dose de $0,5-1 \mathrm{mg} /$ 
$\mathrm{kg}$ e em gatos 2-5 mg, $\mathrm{VO}, \mathrm{q} 8 \mathrm{~h}$ e o midazolam na dosagem de 0,06-0,22 mg/kg, IM, IV ou $0,1 \mathrm{mg} / \mathrm{kg}$, IV para cães e gatos (ANDRADE, 2002). Na doença espinhal pode-se utilizar os benzodiazepínicos para o alívio dos espasmos musculares, sendo considerado um tratamento adjuvante no tratamento da dor nesses pacientes (PAPICH, 2004). Chrisman et al. (2005), cita o uso do diazepam 0,5-2 mg/ $\mathrm{kg}, \mathrm{VO}, \mathrm{q} 6-8 \mathrm{~h}$ na doença do disco intervetebral e na espondilomielopatia cervical (síndrome de wobbler).

Nos casos de tétano quando necessário a manutençãodarespiraçãoartificial,pode-sepromover um relaxamento da musculatura respiratória à base de bloqueadores neuromuscularesdo tipo curare (CANAL; LOPES; CANAL, 2006), já os espasmos musculares são controlados através do uso de diazepam $(0,5-2 \mathrm{mg} / \mathrm{kg}$ IV) ou clorpromazina $(0,5$ $\mathrm{mg} / \mathrm{kg}, \mathrm{IV}) \mathrm{q} 8 \mathrm{~h}$ (TAYLOR, 2006).

Nos casos das câimbras musculares que são vistas com maior freqüência em cães, principalmente naqueles das raças Greyhound e Scottish Terrier, podem ser usados também a levomepromazina ou o diazepam (SILVA et al., 2006)

\section{Vitaminas}

As vitaminas são substâncias necessárias em pequenas quantidades no organismo. Em geral, funcionam como catalisadoras ou reguladoras do metabolismo. Podem ser classificadas com hidrossolúveis e lipossolúveis. As vitaminas hidrossolúveis são ácido ascórbico (vitamina C) e as vitaminas do complexo B; as vitaminas lipossolúveis são as vitaminas A, D, E e K. Tradicionalmente, as vitaminas utilizadas na terapêutica do sistema nervoso são: tiamina $\left(\mathrm{B}_{1}\right)$, piridoxina $\left(\mathrm{B}_{6}\right)$, cobalamina $\left(\mathrm{B}_{12}\right)$, vitamina $\mathrm{E}$ e vitamina C (NISHIOKA; ARIAS, 2005).

As vitaminas B, C e E são freqüentemente utilizadas no tratamento de algumas doenças neurológicas. Nos casos de deficiência, estas vitaminas têm indicação precisa, porém pouco se sabe sobre seus efeitos nas doenças neurológicas decorrentes de outras etiologias. Algumas doenças nutricionais ocasionadas pela deficiência seletiva ou pelo excesso de ingredientes podem ter implicações neurológicas. Entretanto, ainda existem dúvidas quanto à necessidade ou benefício das vitaminas em muitas doenças (NISHIOKA; ARIAS., 2005).

\section{Vitamina $B$}

Em caninos e felinos, os sinais clínicos da deficiência de tiamina são anorexia, ataxia proprioceptiva, ventroflexão do pescoço, coprofagia, consciência diminuída, postura em base ampla, cifose, êmese, paraparesia espástica progressiva, andar em círculos, convulsões generalizadas, opistótono, coma e morte (BRAUND, 1993; NISHIOKA \& ARIAS, 2005). A deficiência natural de tiamina é pouco freqüente em cães e gatos e costuma ser decorrente da presença de fatores antitiamina nos alimentos, ao invés de uma deficiência vitamínica absoluta (NISHIOKA; ARIAS, 2005).

A deficiência de tiamina canina e felina bloqueia as vias metabólicas aeróbicas do SNC. O primeiro passo consiste na reversão da afecção imediata com cloridrato de tiamina injetável, na dose de $10 \mathrm{mg} /$ $\mathrm{kg}$. Muitos pacientes afetados são mantidos com suplementação vitamínica durante 1-2 semanas após a alta hospitalar, sendo a terapia iniciada logo, os pacientes recuperar-se-ão completamente (FENNER, 1997). A administração intramuscular de cloridrato de tiamina por alguns dias na dose de $25-50 \mathrm{mg} / \mathrm{dia}$ em cães e de $10-20 \mathrm{mg} / \mathrm{dia}$ em gatos, mesmo em animais severamente afetados, resulta na remissão completa do quadro (BRAUND, 1993).

\section{Vitaminas $C$ e $E$}

A vitamina $C$ e E são essenciais e agem como antioxidantes, varredores de radicais livre e nutrientes para as células, protegendo a membrana 
e os componentes citoplasmáticos das alterações produzidas pelos radicais livres (ARANHA et al., 2000).

A mielopatia degenerativa e disfunção cognitiva são exemplos de afecções em que tem sido proposta a suplementação vitamínica de vitaminas $\mathrm{C}$ e E, contudo não existe clara evidência do benefício destas medicações até o presente momento. Também na cinomose a vitamina $\mathrm{C}$ e E podem ser utilizadas (NISHIOKA \& ARIAS, 2005). Animais com cinomose nervosa tratados com corticosteróides e com as vitaminas $C$ e E apresentaram melhora clínica (TUDURY; BAHR ARIAS; BOSELLI, 1997). Na síndrome da disfunção cognitiva a vitamina E, 30 UI/kg/dia (não excedendo 400 UI, q12h), constitui um antioxidante com efeitos neuroprotetores potente e facilmente disponível, podendo apresentar benefícios (CHRISMAN et al., 2005).

Com objetivo de reduzir a progressão da doença nos casos de mielopatia degenerativa, pode-se utilizar a vitamina $\mathrm{E}$, reduzindo assim os danos teciduais decorrentes dos radicais livres, porém altas doses de vitamina E pode inibir a coagulação e devem ser evitadas em animais com coagulopatias (NISHIOKA \& ARIAS, 2005). Administração de vitamina E $52 \mathrm{UI} /$ dia podem reduzir ou eliminar as cãibras musculares (CHRISMAN et al., 2005).

Em animais como o cão e o gato, o ácido ascórbico (vitamina C) é sintetizado no fígado, a partir da glicose. A vitamina C reduz a susceptibilidade a infecções (HOUPT; REISNER, 1997). Foi demonstrado que o ácido ascórbico pode suprimir o crescimento viral em células que apresentam infecções crônicas e agudas por diferentes vírus. Também estimulam a atividade fagocítica, a produção e a função das células T (NISHIOKA \& ARIAS, 2005).

Altas doses de vitamina $\mathrm{C}$ podem ser utilizadas objetivando a redução da progressão da doença nos casos de mielopatia degenerativa. Porém altas doses podem induzir a diarréia, podendo-se iniciar o tratamento com baixas doses e posteriormente aumentando-se à dose, caso tolerado utiliza-se à dose de 250-500mg, VO, q8-24h (CHRISMAN et al., 2005).

\section{Conclusões}

Diversos são os fármacos atualmente indicados para o tratamento das diferentes afecções neurológicas que acometem cães e gatos, cada um com suas indicações e peculiaridades específicas. Para que o uso seja feito de forma correta e adequado, o diagnóstico preciso da condição clínica do paciente, bem como das características específicas dos fármacos são essenciais para o sucesso no tratamento das afecções neurológicas de cães e gatos.

\section{Referências}

ADEODATO, A. G. Epilepsia canina: avaliação do brotameto de fibras musgosas hipocampais e do uso de topiramato como droga antiepiléptica adjuntiva. 2005. Tese (Doutor em Ciências) - Universidade Federal de São Paulo, Escola Paulista de Medicina, São Paulo.

AMARAL, H. A.; LARSSON, M. H. M. Estudo da variação da concentração sérica de fenobarbital em cães cronicamente medicados. Brazilian journal of veterinary research and animal science, São Paulo, v. 43, n. 4, p. 435-441, 2006.

ANDRADE, S. F. Manual de terapêutica veterinária. 2. ed. São Paulo: Roca, 2002.

ARANHA, F. Q.; BARROS, Z. F.; MOURA, L. S. A.; GONÇALVES, M. C. R.; BARROS, J. C.; METRI, J. C.; SOUZA, M. S. O. Papel da vitamina $\mathrm{C}$ sobre as alterações orgânicas no idoso. Revista de Nutrição, Campinas, v. 13, n. 2, p. 90-97, 2000.

ARIAS, M. V. B.; NETO, O. P. Emprego do fenobarbital no controle da epilepsia canina-revisão. Clinica veterinária, São Paulo, ano 4, n. 23, p. 25-28, 1999.

BAGLEY, R. S. Fundamentals of veterinary clinical neurology. Iowa: Blackwell publishing, 2005. Cap. 14, p. 323-349.

BERGMAN, R.; LANZ, O.; SHELL, L. A review of experimental and clinical treatments for acute spinal cord injury. Veterinary medicine, Kansas, v. 95, n. 11, p. 855$866,2000$. 
BISTNER, S. I.; FORD, R. B.; RAFFE, M. R. Manual de procedimentos veterinários e tratamento emergencial. 7. ed. São Paulo: Roca, 2002. Seção 1, p. 11-14.

BOOTHE, D. M. Anticonvulsant therapy in small animals. Clinical pharmacology and therapeutics, Saint Louis, v. 28, n. 2, p. 411-423, 1998.

BRAUND, K. G. Spinal trauma. In: Clinical syndromes in veterinary neurology. 2. ed. St Louis: Mosby, 1993. Cap. 3, p. 261-266.

BRAUND, K. G. Distúrbios dos nervos periféricos. In: ETTNGER, S. J.; FELDMAN, E. C. Tratado de medicina interna. 1997. v. 1, cap. 85, p. 989-1038.

BRAUND, K. G. Degenerative disorders of central nervous system of central nervous system. In: BRAUND, K. G. (Ed.). Clinical neurology in small animals: localization, diagnosis and treatment. New York: International veterinary information service, 2003. Disponível em: <http://www.ivis.org $>$. Acesso em: 10 maio. 2009.

BULLOCK, R. Mannitol and other diuretics in severe neurotrauma. New horizons, Baltimore, v. 3, n. 3, p. 448$451,1995$.

CANAL, I. H.; LOPES, F. J. C.; CANAL, R. B. Tétano: também em animais de companhia. Revista Nosso Clínico, São Paulo, v. 53, n. 1, p. 48-58, 2006.

CARROLL, G. L. Tratamento da dor perioperatória In: FOSSUM, T. W.; HEDLUND, C. S.; HULSE, D. A.; JOHNSON, A. L.; SEIM III, H. B.; WILLARD, M. D.; CARROLL, G. L. Cirurgia de Pequenos Animais. 5. ed. São Paulo: Roca, 2005. Cap. 12, p. 90-99.

CHRISMAN, C.; MARIANI, C.; PLATT, S; CLEMMONS, R. Neurologia para Clínico de Pequenos Animais. São Paulo: Roca, 2005. p. 3-336.

CHRISMAN, C. L. Medical management of the neurologic patient. In:__. Problems in small animal neurology. 2. ed. Londres: Oxford University Press, 1991. Cap. 6, p. 119-129.

CHRISMAN, C. L. Convulsões. In: ETTINGER, S. J.; FELDMAN, E. C. Tratado de medicina interna. 4. ed. São Paulo: manole, 1997. v. 1, Cap. 33, p. 210-216.

COATES, J. R. Tail and bladder dysfunction. In: PLATT, S. R.; OLBY, N. J. Manual of canine and feline neurology. 3. ed. British: BSVA, 2004. Cap. 18, p. 302-319.

COATES, J. R.; BARONE, G.; DEWEY, C. W. Procarbazine as adjunctive therapy for treatment of dogs with presumptive antemortem diagnosis of granulomatous meningoencephalomyelitis: 21 cases (1998-2004). Journal of Veterinary internal medicine, Lawrence, v. 21, n. 1, p. 100-106, 2007.
COATES, J. R.; SORJONEN, D. C.; SIMPSON, S. T.; COX, N. R.; WRIGHT, J. C. HUDSON, J. A.; FINNBODNER, S. T.; BROWN, S. A. Clinicopathologic effects of a 21-aminosteroid compound (U74389G) and high-dose methylprednisolone on spinal cord function after simulated spinal cord trauma. Veterinary surgery, Philadelphia, v. 24, n. 2, p. 128-139, 1995.

DEWEY, C. W. A practical guide to canine and feline neurology. England: Blackwell publishing, 2003. p. 3-547.

DEWEY, C. W.; BUDSBERG, S. C.; OLIVER, J. J. E. Principles of head trauma management in dogs and cats- part II. Compendium on continuing education for the practicing veterinarian, Princeton, v. 14, n. 2, p. $177-$ 193, 1993.

EWAN, R. C. Vitaminas. In: DUKES, H. H. Fisiologia dos animais domésticos. 11. ed. Rio de Janeiro: Guanabara Koogan, 1996. Cap. 28, p.457-468.

FARNBACH, G. C. Serum concetrations and efficacy of phenytoin Phenobarbital and primidona in canine epilepsy. Journal of the American Veterinary Medical Association, Schaumburg, v. 184, n. 9, p. 1117-1120, 1984.

FENNER, W. R. Moléstias do encéfalo. In: ETTINGER, S. J.; FELDMAN, E. C. Tratado de medicina interna. 4. ed. São Paulo: Manole, 1997. v. 1, Cap. 82, p. 819-889.

FISCHER, J. R.; LANE, I. F. Medical treatment of voiding dysfunction in dogs and cats. Veterinary Medicine, Kansas, v. 98, n. 1, p. 67-74, 2003.

FRANKLIN, R. T. The use of corticosteroides in treating cerebral edema. Continuing education, New York, v. 6, n. 5, p. 442-447, 1995.

GASKILL, C. L.; BURTON, S. A.; GELENS, H. C. J.; IHLE, S. L.; MILLER, J. B.; SHAW, D. H.; BRIMACOMBE, M. B.; GRIBB, A. E. Effects of phenobarbital treatment on serum thyroxine and thyroidstimulating hormone concentrations in epileptic dogs. Journal of the American Veterinary Medical Association, Schaumburg, v. 215, n. 4, p. 489-496, 1999.

GENNARI, S. M.; SOUZA, S. L. P. Neosporose. Veterinary Practice News, ano 9, n. 59, p. 11-13, 2002.

GUAJAR, J.; HESDORFFER, D. C. Steroids CRASH out of head-injury treatment. The Lancet Neurology, London, v.3, n.12, p.708, 2004.

GNIRS, K. Ciclosporin treatment of suspected granulomatous meningoencephalomyelitis in three dogs. Journal Of Small Animal Practice, Oxford, v. 47, n. 4, p. 201-206, 2006. 
HOUPT, K. A.; REISNER, I. R. Distúrbios comportamentais. In: ETTINGER, S. J.; FELDMAN, E. C. Tratado de medicina interna. 4. ed. São Paulo: Manole, 1997. v. 1, Cap. 40, p. 249-261.

INTELIZANO, T. R.; SANTOS, P. R.; FUTEMA, F.; OTSUKI, D. A.; ALMEIDA, T. I. Técnicas de anestesia local. In: FANTONI, D. T.; CORTOPASSI, S. R. G. Anestesia em cães e gatos. São Paulo: Roca, 2002. Cap.19, p. 199-208.

LEE, G.; DALLAS, S.; HONG, M.; BENDAYAN, R. Drug Transporters in the Central Nervous system: brain barriers and brain parenchyma considerations. Pharmacological Reviews, Baltimore, v. 53, n. 4, p. 569596, 2001.

LECOUTEUR, R. A.; CHILD, G. Afecções da medula espinhal. In: ETTINGER, S. J.; FELDMAN, E. C. Tratado de medicina interna. 4. ed. São Paulo: Manole, 1997. v. 1, p. 890-1025.

LIN, K.; SÁ, P. N. D. Aspectos farmacocinéticos e farmacodinâmicos dos agentes antibacterianos no SNC. Arquivos catarinenses de medicina, Florianopolis, v. 31, n. $1 / 2$, p. $25-30,2002$.

LIS, C. G. Desordens comportamentais. In: PELLEGRINO, F. C.; SURANITI, A.; GARIBALDI, L. Síndromes neurológicas em cães e gatos. São Paulo: Interbook, 2003. Cap. 19, p. 264-279.

LORENZ, M. D.; KORNEGAY, J. N. Neurologia veterinária. 4. ed. Barueri: Manole, 2006. Cap. 13, p. 323-344.

MAGUIRE, P. J.; FETTMAN, M. J.; SMITH, M. O.; GRECO, D. S.; TURNER, A. S.; WALTON, J. A.; OGILVIE, G. K. Effects of diet on pharmacokinetics of phenobarbital in healthy dogs. Journal of the American Veterinary Medical Association, v. 219, n. 6, p. 847-856, 2000.

MANNO, E. M. New management strategies in the treatment of status epilepticus. Mayo Clinic Proceedings, Rochester, v. 78, n. 4, p. 508-518, 2003.

MCDONALD, R. K.; LANGSTON, V. C. Uso de corticosteróides e medicamentos antiinflamatórios não corticosteróides. In: ETTINGER, S. J.; FELDMAN, E. C. Tratado de medicina interna. 4. ed. São Paulo: manole, 1997. v. 1, Cap. 59, p. 406-419.

MORAES, R. M. O.; OLIVEIRA, I. R. Antipsicóticos. In: SILVA, P. Farmacologia. 7. ed. Rio de Janeiro: Guanabara Koogan, 2006. Cap. 34, p. 313-328.

MOREIRA, C. F.; MARTINS, C. S.; SALGADO, D. Miastenia grave em cães e gatos- revisão. Clinica Veterinária, São Paulo, v. 11, n. 62, p. 46-64, 2006.
MOREIRA, J. C. Controle da dor em UTI: identificação da dor através do comportamento. In: RABELO, R. C.; CROWE JUNIOR, D. T. Fundamentos de terapia intensiva veterinária em pequenos animais. Rio de Janeiro: L. F. Livros, 2005. Cap. 43, p. 495-506.

NAU, R.; SORGEL, F.; PRANGE, H. W. Pharmacokinetic optimization of treatment of bacterial central nervous system infections. Clinical pharmacokinetics, Auckland, v. 35, n. 3, p. 223-246, 1998.

NISHIOKA, C. M.; ARIAS, M. V. B. Uso de vitaminas no tratamento de doenças neurológicas de cães e gatos. Clinica Veterinária, São Paulo, v. 10, n. 55, p. 62-72, 2005.

PAIXÃO, T. A.; SANTOS, R. L. Encefalite por neospora caninum e toxoplasma gondii em cães. Clínica Veterinária, São Paulo, v. 9, n. 48, p. 44-52, 2004.

PAPICH, M. G. Drug therapy fot diseases of the central nervous system. In: PLATT, S. R.; OLBY, N. J. manual of canine and feline neurology. 3. ed. Britsh: BSAVA, 2004. Cap. 22, p. 368-384.

PEARCE, L. K. Potassium bromide as an adjunct to Phenobarbital for the management of uncontrolled seizures in dogs. Programme Veterinary Neurology, Washington, v. 1, n. 1, p. 95-101, 1990.

PELLEGRINO, F. Epilepsia e síndromes epilépticas. In: PELLEGRINO, F. C.; SURANITI, A.; GARIBALDI, L. Síndromes neurológicas em cães e gatos. São Paulo: Interbook, 2003. Cap. 13, p. 192-215.

PLATT, S. R. Recommendations for corticosteroid use in neurological diseases. $20^{\text {th }}$ ed. Dallas: American College of Veterinary Internal Medicine, 2002. p. 370-372.

PLATT, S. R.; ABRAMSON, C. J.; GAROSI, L. S. Administering corticosteroids in neurological diseases. Compendium On Continuing Education For The Practicing Veterinarian, Princeton, v. 10, n. 3, p. 210219, 2005.

PODELL, M. Seizures. In: PLATT, S. R.; OLBY, N. J. Manual of canine and feline neurology. 3. ed. British: BSVA, 2004. Cap. 7, p. 97-112.

SACCO, P. C. N. Relaxantes Musculares de ação central. In SILVA, P. Farmacologia. 7. ed. Rio de Janeiro: Guanabara koogan, 2006. Cap. 40, p. 379-388.

SHELTON, G. D. Myasthenia gravis and disorders of neuromuscular transmission. Veterinary Clinics Of North America: small animal practice, Philadelphia, v. 32, n. 1, p. 189-206, 2002. 
SILVA, S. R. A. M.; NETO, P. I. N.; TUDURY, E. A.; FANTONI, D. T. Anestesia de cães e gatos com distúrbios neurológicos- artigo de revisão. Clinica veterinária, São Paulo, v. 11, n. 64, p. 34-46, 2006.

SILVEIRA, M. A. B. Ansiolíticos. In: SILVA, P. Farmacologia. 7. ed. Rio de Janeiro: Guanabara koogan, 2006. Cap. 35, p. 329-336.

SPINOSA, H. S.;GORNIAK, S. L.; BERNARD, M. M. Farmacologia Aplicada à Medicina Veterinária. 2. ed. Rio de Janeiro: Guanabara Koogan, 1999. Cap. 26, p. 269-278.

STIRLING, D. P.; KOOCHESFAHANI, J. D. S.; TETZLAFF, W. Minocycline as a neuroprotective agent. The neuroscientist, Baltimore, v. 11, n. 4, p. 308-322, 2005.

TAYLOR, S. M. Distúrbios neuromusculares. In: NELSON, R. W.; COUTO, C. G. Medicina interna de pequenos animais. 3. ed. Rio de Janeiro: Elsevier, 2006. Cap. 67, 70, 71, p. 945, 971, 978.

THOMAS, W. B. Use of corticosteroids in neurology. In: TUFTS ANIMAL EXPO CONFERENCE PROCEEDINGS, 2002, Kansas. Proceedings... Kansas: Small Animal Clinician, 2002. Disponível em: $<$ http:// www.vin.com>. Acesso em: 28 maio 2008.
THOMAS, W. B. Seizures and Narcolepsy. In: DEWEY, C. W. A practical guide to canine and feline neurology. England: Blackwell publishing, 2003. Cap. 6, p. 193212.

TILLEY, L. P.; SMITH JUNIOR, F. W. K. Consulta veterinária em 5 minutos espécies canina e felina. 2. ed. São Paulo: Manole, 2003. 1013 p.

TUDURY, E. A.; BAHR ARIAS, M. V.; BOSELLI, C. C. Avaliação de tratamentos realizados em cães suspeitos de padecer de cinomose nervosa - pré experimento. In: CONGRESSO BRASILEIRO DA ANCLIVEPA, 14., 1997, Curitiba. Anais... Curitiba, 1997. v. 1. p. 3.

VRIES, H. E.; KUIPER, J.; BOER, A. G., VAN BERKEL, T. J. C.; BREIMER, D. D. The blood-brain barrier in neuroinflammatory diseases. Pharmacological Reviews, Baltimore, v. 49, n. 2, p. 25-30, 1997.

ZARFOSS, M.; SCHATZBERG, S.; VENATOR, K.; CUTTER SCHATZBERG, K.; CUDDON, P.; PINTAR, J.; WEINKLE, T.; SCARLETT, J.; DELAHUNTA, A. Combined cytosine arabinoside and prednisone therapy for meningoencephalitis of unknown aetiology in 10 dogs. Journal Of Small Animal Practice, Oxford, v. 47, n. 10 , p. $588-595,2006$. 